\title{
Noise Level Status in Siddharthanagar Municipality, Rupandehi, Nepal
}

\author{
Lakshmi Nath Bhattarai \\ Department of Physics, Butwal Multiple Campus, Nepal \\ e-mail: lakshmibhattarai@gmail.com
}

\begin{abstract}
Undesirable sound for human hearing is called as noise. It was measured at the selected locations of silent, residential and commercial zones of Siddharthanagar Municipality by using Dick Smith Digital Sound Level Meter Q 1362 for 'A' weighting in day time at 9:00 AM to 6:00 PM in the month of November and December 2012. The result shows that at each location the Leq noise levels are above than the noise level standard prescribed by Government of Nepal and WHO. Maximum Leq of $81.9 \mathrm{~dB}(A)$ was observed at the Bus park of commercial area and minimum $54.5 \mathrm{~dB}(A)$ was observed at Medical College area of silent zone. In other places, the Leq lie in the range $56.2 \mathrm{~dB}(A)$ to $81.9 \mathrm{~dB}(A)$. The study showed that the places lying along highways have high level of noise which is due to bad condition of roads, vehicles and unnecessary use of horns.
\end{abstract}

Keywords: Noise pollution, decibel, Noise level, Silent zone, Commercial zone.

\section{INTRODUCTION}

Sound that is undesirable for human hearing is called as noise. When there is lot of noise in the environment it constitutes noise pollution. Noise pollution is regarded as technology generated problem. The industrialization, scientific and technological developments are contributing to the development of society but at the same time these are also the main causes of environmental pollution. Noise pollution is recognized as a major problem for the quality of life in Urban areas all over the world (Ozer et. al., 2009). The noise pollution is increasing day by day along with increase in the number of vehicles. The noise pollution in roads is produced due to screeching tyres, squealing brakes, jumping of vehicles and blasting horns. Noise pollution is also produced by radio, television, music systems depending upon their volume. The home appliances like washing machine, vacuum cleaner, mixer grinder also produce noise pollution.

Noise is technically one of the complex and least understood form of pollution. Like other forms of pollution, noise pollution also has different effects on human life, animals and property. Effects like: decrease in efficiency of a person, decrease in concentration, fatigue, abortion, blood pressure, temporary and permanent deafness, poor quality of crops, effects on building, bridge and monuments, etc. have been observed due to effect of noise pollution.

The major health effect induced by the noise pollution is observed as lack of concentration. Irritation, fatigue and headache were also other major health effects caused by noise pollution. Chest pain and nausea are the least health effects observed (Joshi, 2003).

The noise pollution is measured in Decibel $(\mathrm{dB})$ unit. Human ears are able to detect the sound intensity from $10^{-12} \mathrm{~W} / \mathrm{m}^{2}$ at low to $1 \mathrm{~W} / \mathrm{m}^{2}$ at high. Above 1.0 $\mathrm{W} / \mathrm{m}^{2}$ there is pain or damage to hearing. A sound level scale is derived which compares the intensity of sound with reference to the threshold of hearing $\left(10^{-12} \mathrm{~W} / \mathrm{m}^{2}\right)$. The scale is called as decibel scale which is defined as,

Sound Intensity Level $\mathbf{L}_{\mathbf{I}}(\mathrm{dB})=10 \log _{10}\left(\mathrm{I} / \mathrm{I}_{0}\right) \ldots(1)$ where, $\mathrm{L}_{\mathrm{I}}$ is sound Intensity level corresponding to the intensity $I$ and $I_{o}$ is the intensity at threshold of hearing.

\section{NOISE LEVEL INDICES}

The statistical parameters which are used to describe the intensity of Sound level at a point or place are called as noise level indices. The commonly used noise level indices are: $\mathbf{L}_{\mathrm{eq}}, \mathbf{L}_{10}, \mathbf{L}_{50}, \mathbf{L}_{90}, \mathbf{L}_{\text {max }}, \mathbf{L}_{\text {min }}$ etc. 
The noise level at a particular place varies with time and surrounding condition. The equivalent continuous sound intensity level is widely used around the world as an index for noise. The average value of sound energy over a particular time period (T) is called as equivalent continuous sound level and is denoted by $\mathbf{L}_{\text {eq }}$. It is the continuous steady sound level that would have the same total acoustic energy as real fluctuating noise over the same interval of time. Mathematically it is given by,

$\mathrm{L}_{\text {eq }}=10 \log _{10}\left(\frac{1}{\mathrm{~T}} \int 10^{0.1 \times \mathrm{Li}} \mathrm{dt}\right)$

where, $\mathrm{T}$ is time period and $\mathrm{L}_{\mathrm{i}}$ is the noise level at the $i^{\text {th }}$ sample.

For discrete methodology as used by Olayinka et al. (2010) $\mathrm{L}_{\text {eq }}$ is given by,

$\mathrm{L}_{\mathrm{eq}}=10 \log _{10}\left(\frac{1}{\mathrm{~N}} \sum_{\mathrm{i}=1}^{\mathrm{N}} \mathrm{f}_{\mathrm{i}} \times 10^{0.1 \times \mathrm{L}_{\mathrm{i}}}\right) \ldots \ldots \ldots \ldots$

where, $\mathrm{N}=$ total number of data observed and $\mathrm{f}_{\mathrm{i}}=$ fraction of time for that the sound level is in the $i^{\text {th }}$ interval which is 1 second in slow mode of Sound level meter.

Similarly other terms are defined as:

$\mathbf{L}_{10}: \mathrm{L}_{10}$ is the sound level in $\mathrm{dB}$ that is exceeded $10 \%$ of the time over measurement period.

$\mathbf{L}_{\mathbf{5 0}}: \mathrm{L}_{50}$ is the sound level in $\mathrm{dB}$ that is exceeded $50 \%$ of the time over measurement period.

$\mathbf{L}_{\mathbf{9 0}}: \mathrm{L}_{90}$ is the sound level in dB that is exceeded $90 \%$ of the time over measurement period.

$\mathbf{L}_{\max }: \mathrm{L}_{\max }$ is the maximum sound level measured during the measurement period with the sound meter set on SLOW response.

$\mathbf{L}_{\text {min }}: \mathrm{L}_{\min }$ is the maximum sound level measured during the measurement period with the sound meter set on SLOW response. $\mathbf{L}_{\text {eq }}, \mathbf{L}_{\mathbf{1 0}}, \mathbf{L}_{\mathbf{5 0}}, \mathbf{L}_{\mathbf{9 0}}, \mathbf{L}_{\text {max }}$ and $\mathbf{L}_{\text {min }}$ values measured in A- weighting are expressed as $\mathbf{L}_{\mathbf{A e q}}, \mathbf{L}_{\mathbf{A 1 0}}, \mathbf{L}_{\mathbf{A 5 0}}, \mathbf{L}_{\mathbf{A 9 0}}, \mathbf{L}_{\mathbf{A m a x}}$ and $\mathbf{L}_{\text {Amin }}$ respectively.
A decibel meter also called as the sound level meter is modeled to measure accurately and objectively the sound or noise level present in the environment. However, this meter cannot measure the subjective loudness experienced by human ear (Schlanger, 2008). The sound level can be measured in two ' $A$ ' and ' $C$ ' weightings. ' $A$ ' weighting enables the meter to respond in the same manner as the human ear, which increases or decreases amplitude over the frequency range and ' $\mathrm{C}$ ' weighting measures for flat response with no increase or decrease of amplitude over the frequency range.

WHO has prescribed the safe noise level for a city as $45 \mathrm{~dB}$. In United States the noise level of $65 \mathrm{~dB}$ at day time and $55 \mathrm{~dB}$ at night time in streets is prescribed. Anyone crossing the limit is regarded as causing noise pollution.

In Nepal also Government of Nepal has formulated noise level standard for different area for day and night time. Environment Department has been established under the Ministry of Science, Technology and Environment for monitoring the environmental condition. Noise Level standard formulated by Government of Nepal is in table 1 .

The Digital horns in Vehicles in the Silent zones are prohibited. Anyone avoiding the rule is punished by traffic police. Airplanes cause highest sound about $150 \mathrm{~dB}$. The road vehicles are also the great contributor of noise pollution. These vehicles include trucks, bushes, tractors, motorcycles, cars etc. In urban areas the electric generators also produce a lot of noise.

Table1: Noise Level Standard of Nepal (2069)

\begin{tabular}{|l|l|c|c|}
\hline S. & \multicolumn{2}{|c|}{ Area } & \multicolumn{2}{c|}{ Noise Level dB(A) } \\
\cline { 3 - 4 } N. & & Day time & Night time \\
\hline 1 & Silent Zone & 50 & 40 \\
\hline 2 & Industrial Area & 75 & 70 \\
\hline 3 & Business Area & 65 & 55 \\
\hline 4 & Rural Residential Area & 45 & 40 \\
\hline 5 & Urban Residential Area & 55 & 45 \\
\hline 6 & Mixed Residential Area & 63 & 40 \\
\hline
\end{tabular}


The noise level measurement is a common practice in many places of various countries. Some of the relevant studies are mentioned here. The noise level measured at selected place of Pudukkottai, Tamilnadu, found that vehicular traffic and pressure horn are the main cause of noise pollution in the city(Ravichandran et al., 2000). Assessment of noise level in Burdwan town, West Bengal found that sound level lies within the range of 64-85 $\mathrm{dB}(\mathrm{A})$ or above in different time at different places (Datta et al., 2006). The noise level measured in the city of Deharadun India showed that the noise level varied from maximum $102.7 \mathrm{~dB}(\mathrm{~A})$ to minimum $47.7 \mathrm{~dB}(\mathrm{~A})$ at the selected places with the noise level in the silent zones above the prescribed standard values (Ziaudin et al., 2007).Study of noise pollution carried out in Rorkee city by R.K. Mishra, S. Rangnekarand M. Parida (2009) showed the high level of noise pollution due to automobiles and loudspeakers. The measurement of noise level in city of Tokata, Turkey found the level above 65 $\mathrm{dB}(\mathrm{A})$ at 76.9 percent points and below $65 \mathrm{~dB}(\mathrm{~A})$ at 23.1 percent points of observation (Ozer et al., 2009). The assessment of noise pollution in Gwalior MP India carried out by K. A. Wani and Y.K. Jaiswal( 2010) showed that the noise level varied from 74.3$119.2 \mathrm{~dB}(\mathrm{~A})$ in railway station of commercial area to $45.5-65.8 \mathrm{~dB}(\mathrm{~A})$ at Jiwaji Campus of silent zone. The study of noise levels at different locations in Dhaka City showed that average noise level at every location varied within the range of $80-90 \mathrm{~dB}(\mathrm{~A})$ which exceeded the acceptable limit of $60 \mathrm{~dB}(\mathrm{~A})$ set by Department of Environment, Bangladesh (Hassan\& Alam, 2013).The noise level study carried out by Khan, M. W. et al.,(2010)showed that Karachi is facing an enormous problem of exceedingly high levels of traffic noise with the mean values of noise level in the commercial and residential areas as $95.75 \mathrm{~dB}(\mathrm{~A})$ and $60 \mathrm{~dB}(\mathrm{~A})$ respectively.

The noise level survey carried out by Sapkota et al.(1999) shows that the noise level varied from 65.1 $\mathrm{dB}(\mathrm{A})$ to $74.5 \mathrm{~dB}(\mathrm{~A})$ in heavy traffic area and 63.2 $\mathrm{dB}(\mathrm{A})$ to $72.1 \mathrm{~dB}(\mathrm{~A})$ in low traffic area of Kathmandu city. The study of Noise level carried out by Nepal
Health Research Council \& WHO in commercial area of Kathmandu valley shows maximum level of $77 \mathrm{~dB}(\mathrm{~A})$ at Kupondole and minimum level of 58 $\mathrm{dB}(\mathrm{A})$ at Tribhuvan University gate (CBS, 2008) . Krishnamurthy et al.,(2007) reported that noise level in Banepa city of Nepal varies from 60.1 $\mathrm{dB}$ (A) to $110.2 \mathrm{~dB}$ (A). The study of Noise level around Tribhuvan International Airport carried out by Mohan Bhattarai(2009) shows highest noise level up to $101.5 \mathrm{~dB}(\mathrm{~A})$ at Gothatar and least 63.5 $\mathrm{dB}(\mathrm{A})$ at Datidol.

\section{MATERIALS AND METHODS}

Siddharthanagar Municipality is located in Rupandehi district of the Western Development Region of Nepal. It is district head quarter of Rupandehi district. Geographically, it is located between $27^{0} 40^{\prime}-27^{0} 44^{\prime}$ north latitude and $83^{\circ} 22^{\prime}$ $83^{\circ} 30^{\prime}$ east longitude. This is one of the main centre of commerce, education, tourism and industry in west Nepal. Siddhartha Highway and Hulaki marga (Sadak) pass through the municipality. Gautam Buddha airport lies in this Municipality. In average 12 flights take place from here per day. This municipality lies in the southern border of Nepal. This is also one of the gateways of Nepal. The population of this municipality is about 108558 and it covers $36.03 \mathrm{Km}^{2}$ area (Siddharthanagar Municipality, a Brief Introduction, 2068).

For the field study four sites (Buspark, Devkota Chowk, Buddha Chowk and Bank Road) belonging to commercial zone were selected. Four sites (Bhim Hospital, Lumbini Rana-Ambika Eye Hospital, Universal Medical College and Bhairahawa Multiple Campus) belonging to silent zone and Annapurna Tole and Goligarh belonging to residential zone were selected for field study.

The study of noise level was carried out by using a portable digital sound level meter (Dick Smith Digital Sound level Meter Q 1362) which is primarily designed for community noise surveys. Measurements were carried out for ' $\mathbf{A}$ ' weighting at the selected locations of silent, residential and commercial zones in day time at 9:00 AM to 6:00 
PM in the month of November and December 2012. The sound levels were measured at the $15^{\text {th }}$ seconds in the interval of 15 seconds for 10 minutes giving 40 readings at each sampling sites. The readings were taken two times in each sampling sites. The sound level meter was taken in hand at a height of $1.0-1.5 \mathrm{~m}$. and at a distance of $15 \mathrm{~m}$. from the center in roadside of Highway, in the premises of Hospitals and Campus/College and along streets in residential areas. The measurements were carried out under the normal atmospheric condition having no rainfall and high wind speed.

\section{RESULT AND DISCUSSION}

The noise level at a particular location depends upon the distance of source and surrounding conditions. Along roadside it depends upon the density of vehicular flow, types of vehicles, condition of vehicles and condition of road. In smooth and wide road there is less noise in comparison to the rough, damaged and congested road. Table 2 shows the various noise level indices at various sites of the Siddharthanagar Municipality.

Figure 1 illustrates the $\mathrm{L}_{\mathrm{eq}}$ in the selected locations of the Siddharthanagar municipality. The result shows that at each locations the $\mathrm{L}_{\mathrm{eq}}$ noise levels are above than the noise level standard prescribed by Government of Nepal and WHO. Maximum $\mathrm{L}_{\text {eq }}$ of $81.9 \mathrm{~dB}(\mathrm{~A})$ was observed at the Bus park of commercial area and minimum $54.5 \mathrm{~dB}(\mathrm{~A})$ was observed at Medical College area of silent zone. In other places, the $\mathrm{L}_{\text {eq }}$ lie in the range $56.2 \mathrm{~dB}(\mathrm{~A})$ to $81.9 \mathrm{~dB}(\mathrm{~A})$. Figure 1 depicts the equivalent noise level $\mathrm{L}_{\mathrm{eq}}$ observed at various location of the Siddharthanagar Municipality during the measurement period.

Table 2: Noise level indices at various sites of the Siddharthanagar Municipality

\begin{tabular}{|c|c|c|c|c|c|c|c|}
\hline \multirow{2}{*}{ Area/ Zone } & \multirow{2}{*}{ Location } & \multicolumn{6}{|c|}{ Noise level in $\mathrm{dB}(\mathrm{A})$} \\
\hline & & $\mathbf{L}_{10}$ & $\mathbf{L}_{50}$ & $\mathbf{L}_{90}$ & $\mathbf{L}_{\mathrm{eq}}$ & $\mathbf{L}_{\max }$ & $\mathbf{L}_{\text {min }}$ \\
\hline \multirow{4}{*}{ Commercial } & Buddha Chowk & 75.2 & 67.0 & 61.9 & 78.5 & 96.7 & 57.4 \\
\hline & Devkota Chowk & 73.6 & 68.7 & 64.5 & 70.3 & 78.5 & 60.1 \\
\hline & Bus Park & 76.7 & 67.5 & 61.8 & 81.9 & 100.1 & 58.8 \\
\hline & Bank Road & 75.1 & 67.7 & 63.2 & 79.9 & 96.7 & 55.2 \\
\hline \multirow{4}{*}{ Silent } & Bhim Hospital & 61.8 & 52.5 & 48.1 & 56.2 & 64.1 & 47.1 \\
\hline & Eye Hospital & 64.6 & 62.6 & 60.2 & 63.5 & 72.8 & 56.4 \\
\hline & Medical College & 57.6 & 52.5 & 47.7 & 54.5 & 62.0 & 45.6 \\
\hline & Bhairahawa M. Campus & 58.6 & 53.2 & 48.6 & 56.2 & 66.3 & 45.2 \\
\hline \multirow{2}{*}{ Residential } & Annapurna Tole & 61.2 & 52.6 & 47.6 & 56.8 & 65.6 & 45.0 \\
\hline & Goligarh & 60.2 & 53.1 & 46.5 & 56.2 & 64.5 & 45.3 \\
\hline
\end{tabular}

Source: Field survey 2012 


\section{Noise Level Leq in $\mathrm{dB}(\mathrm{A})$}

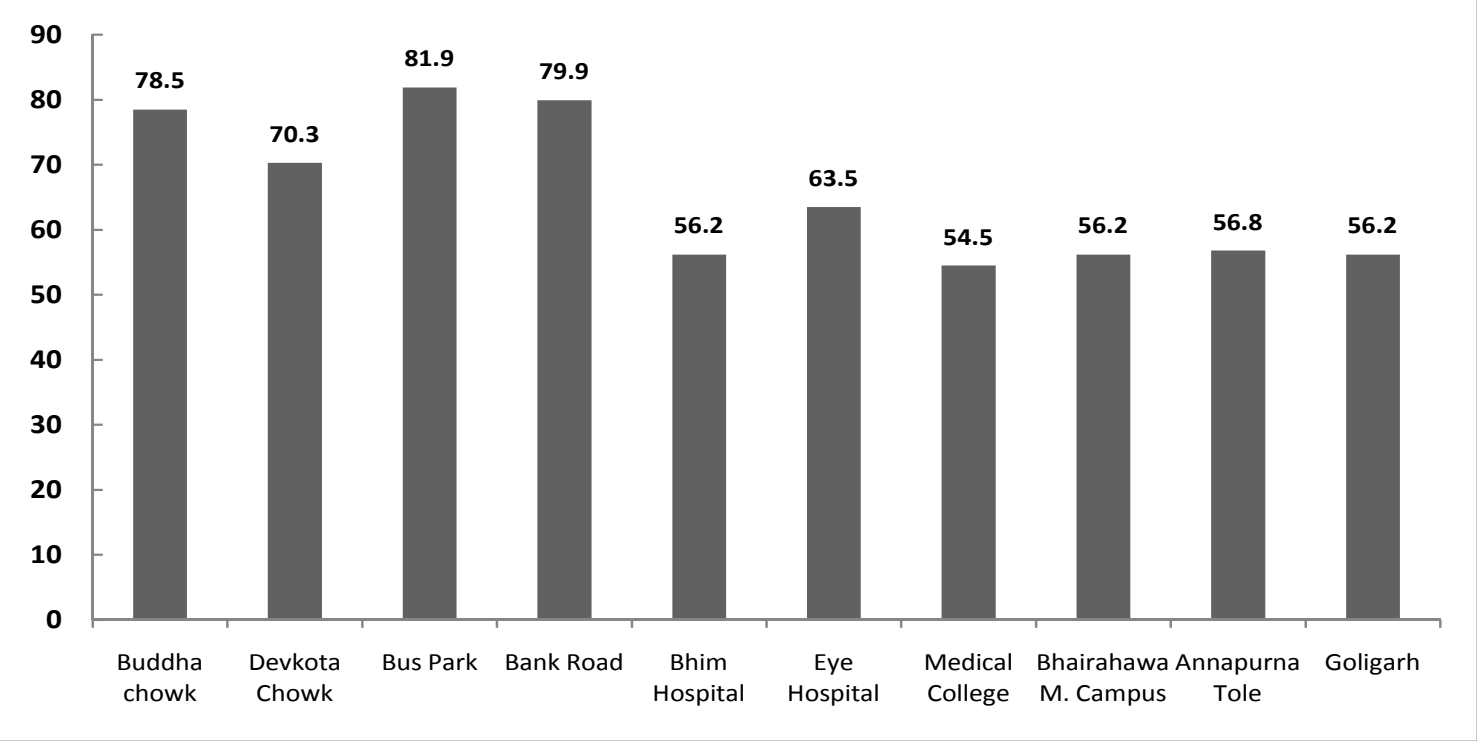

Fig. 1: $\mathrm{L}_{\mathrm{eq}}$ at various sites of the Siddharthanagar Municipality

The difference in noise level at these locations is due to various reasons. Maximum noise level at the Bus Park area is due to the heavy traffic flow and crowded environment. The noise level in this area is also added by the use of pressure horn used by some vehicles. When the source of noise moves away, the noise level at a place reduces significantly which is reflected in the table 2. The low level of noise $54.5 \mathrm{~dB}(\mathrm{~A})$ at Medical College area is due to its location lying away from highway. Though Bhim Hospital premise lies in the commercial area, the noise level around it is found only $56.2 \mathrm{~dB}(\mathrm{~A})$. This low level of noise is due to the building structures around the premise acting as acoustic barrier. Similarly, the low levels of noise at Bhairahawa Multiple Campus, Annapurna Tole and Goligarh area are due to their location being away from the highway and being plants around them. These results suggest that main sources of noise in the Municipality are the vehicles running on the roads.

\section{CONCLUSIONS}

From the study carried out to evaluate the noise level in the selected sites of the Siddharthnagar Municipality following conclusions are drawn:

1. Bus Park is the noisiest place with $\mathrm{L}_{\text {eq }}$ of $81.9 \mathrm{~dB}(\mathrm{~A})$.

2. Medical College is the quietest place with $\mathrm{L}_{\mathrm{eq}}$ of $54.5 \mathrm{~dB}(\mathrm{~A})$.
3. 90 percent sampling sites have noise level above the recommended value of $55 \mathrm{~dB}(\mathrm{~A})$.

4. The main sources of noise in the municipality are the vehicles like buses, trucks, tractors, motorcycles, delivery vans etc. running on the roads and generators during power cut hours.

5. The bad condition of the vehicles especially tractors metallic body and their vibration produce much noise.

6. The bad condition of roads and the drivers' behavior of using horn add more noise.

\section{RECOMMENDATIONS}

In order to reduce the noise pollution level in the study area and in other places following recommendations are suggested:

1. Since transport system is regarded as the major source of noise pollution in the urban areas, technical plans like: road maintenance, expansion of roads, repairing engine, repairing silencer, repairing body parts, limiting the types of vehicles, limiting the speed of vehicles, hours of access, etc. should be implemented.

2. Building acoustic barrier and planting bushy plants along the road sides passing through the urban area, the noise level reaching to residents 
can be substantially reduced.

3. Awareness about the health hazards of noise pollution should be carried out by using different electronic media, print media, flash board, notice board, etc.

4. In order to decrease the noise level peoples' behavior as to speaking loudly, blasting horn, playing the musical instrument and using loud speakers should be changed.

5. The noise level should be assessed in regular manner and noise level map should be prepared in the Municipality area.

6. The noise level standard formulated by the Government should be strictly implemented by the concerned authority.

7. In order to keep the Eye Hospital area silent, acoustic barrier should be made and horn \& speed of vehicles passing through the region should be controlled.

8. Use of pressure horn should be banned in the city area.

\section{ACKNOWLEDGEMENTS}

The author is thankful to University Grants Commission, Nepal for providing financial support to carry out the research work.

\section{RFERENCES}

1. Bhattarai, M. (2009). Assessment of noise level around Tribhuvan International Airport. Unpublished M. Sc. Dissertation, Central Department of Physics, T.U.

2. CBS(2008).Environment Statistics of Nepal. Central Bureau of Statistics, Kathmandu, p58.

3. Datta, J. K., Sadhu,S., Gupta, S., Saha R., Mondal, N. K. and Mukhopadhyay ,B.(2006). Assessment of noise level in Burdwan town, West Bengal, Journal of Environmental Biology, Vol.27(3): 609-612.

4. Hassan, A., Alam, J.B.(2013). Traffic Noise Levels at Different Locations in Dhaka City and Noise Modelling for Construction Equipments;International Journal of Engineering Research and Applications, Vol. 3(2):1032-1040.
5. Joshi, S.K., Devkota, S., Chamling, S., Shrestha, S. (2003). Environmental noise induced hearing loss in Nepal, Kathmandu University Medical Journal, Vol. 1(3): 177-183.

6. Khan, M. W., Memon, M. A., Khan, M. N. \& Khan, M.M. (2010). Traffic Noise Pollution in Karachi, Pakistan, JLUMHS, 09(03): 114-120.

7. Krishnamurthy, V., Majumder, A.K., Khanal, S.N. and Subedi, D.P. (2007). Assessment of Traffic Noise pollution in Banepa, a semi-urban town of Nepal, KathmanduUniversity Journal of Science, Engineering and Technology, Vol.1(IV): 1-9.

8. Mishra, R. K., Rangnekar, S. and Parida, M. (2009). Survey on Noise Pollution and Its Management, Journal of IPHE, India, (4): 30-33.

9. Olayinka, S. Oyedopo and Abdullahi A. Saadu (2010). Evaluation and Analysis of Noise Levels in Ilorin Metropolis, Nigeria, Environ Monit Assess, 160: 563-577.

10. Ozer, S., Yilmaz, H., Yesil, M. and Yesil, P.(2009). Evaluation of Noise Pollution caused byvehicles in the city of Tokata, Turkey, Scientific Research and Essay, 4(11):1205-1211.

11. Ravichandran, C., Chandrasekaran, G. E. and Kumar, M. V. (2000). Noise pollution assessment in Pudukkottai, Tamil Nadu. Polln. Res., 19(3):431-434.

12. Sapkota, B. K., Pokhrel, B., Poudyal, K. and Bhattarai, B. (1999). A Study of Community Noise in Kathmandu Valley, NAST.

13. Schlanger, H.P. (2008). Measuring sound Intensity and Loudness. Retrived from http:// www.suite $101 . \mathrm{com} /$ content/how-loud-isit-a62825,11-11-2010.

14. Siddharthanagar Municipality(2068 B.S).ABrief Introduction of Siddharthanagar Municipality, Siddharthanagar, Rupandehi, Nepal.

15. Wani, K. A. and Jaiswal, Y.K. (2010). Assessment of Noise Pollution in Gwalior M.P. India, Advances in Bioresearch, Vol. 1(1):54-59.

16. WHO (1999). Guidelines for Community Noise, World Health Organization.

17. Ziauddin, A., Bahel, R.S. and Siddiqi, N.A. (2007). Noise Pollution Level in the City of Deharadun, Eco. Env. Cons. 13(4): 891-893. 